\title{
Optimal destabilization of cartels
}

\author{
Ludwig von Auer ${ }^{1}$ (D) Tu Anh Pham ${ }^{1}$
}

Accepted: 16 February 2021 / Published online: 23 February 2021

(c) The Author(s) 2021

\begin{abstract}
This paper introduces an oligopoly model that includes three actors: a cartel (comprising two or more firms that operate like one merged company), a group of competing fringe firms, and a welfare maximizing antitrust authority. The cartel is the Stackelberg quantity leader and the fringe firms are in Cournot competition with respect to the residual demand. The cartel is internally stable if none of its member firms finds it profitable to become a fringe firm. The antitrust authority can destabilize the cartel in the sense of making the cartel internally instable. To this end, the antitrust authority has three policy instruments at its disposal: its own effort, a fine for detected cartels, and a leniency program for cartel members that cooperate with the authority. Taking into account that the use of these instruments is not costless for society, a unique optimal antitrust policy is derived. The analysis reveals that both, the optimal force and mix of the antitrust authority's policy depend on market characteristics such as the efficiency of the authority's operations, the public respect for the rule of law, the ethical standards of the firms' managers, the market volume, and the number of firms operating on the market.
\end{abstract}

Keywords Antitrust - Stability · Leadership model · Oligopoly · Fringe firms · Leniency

JEL Classification L13 · L41

\begin{abstract}
This is a fundamentally revised version of a paper that we presented at IIOC 2017 in Boston and EARIE 2017 in Maastricht. The revised paper was presented at the annual meeting of the Verein für Socialpolitik 2020 in Cologne. We gratefully acknowledge the helpful advice of three anonymous referees. The new manuscript also benefited from suggestions by Laszlo Goerke, Vasily Korovkin, Kebin Ma, Alberto Palermo, Maarten Pieter Schinkel, Armin Schmutzler, Nicolas Schutz and Andranik Stepanyan. Any remaining errors and omissions are of course ours.
\end{abstract}

\footnotetext{
$凶 \quad$ Ludwig von Auer vonauer@uni-trier.de

1 Universität Trier, Trier, Germany
} 


\section{Introduction}

The "prestressing steel cartel" operated on the European market between 1984 and 2002. It agreed to set quotas on the quantities to be supplied to shared clients. The cartel comprised eighteen members competing against six fringe firms. The collusion was complicated by new competitors and by a drop in demand in 1996. In 2002, the cartel was detected. In 2011, it was finally punished by a penalty of almost $€ 270$ million. ${ }^{1}$ The "methionine cartel" operated between 1986 and 1999. It agreed to limit its sales outside the USA and Japan. The cartel had four members competing against two fringe firms. When in 1991 the fringe competitor Novus introduced a successful rival product, the cooperation within the cartel became more difficult. The cartel was detected in 2001 and a year later penalized with a fine of $€ 127$ million. $^{2}$

These two examples suggest that the collusion of cartels is confronted by at least three external threats: the investigations of antitrust authorities, competition from fringe firms, and changes in the market environment. Therefore, our model-based derivation of an effective antitrust policy takes account of three actors: a cartel, a group of competing fringe firms, and an antitrust authority that incorporates into its policy the specific characteristics of the relevant market.

Fringe firms complicate the theoretical analysis, as they raise the issue of cartel stability (d'Aspremont et al. 1983). A cartel is stable if no cartel member has an incentive to become a fringe firm and, at the same time, no fringe firm wants to become a cartel member. Cartel stability usually has been studied in the context of so-called leadership models. These models assume that the cartel acts as Stackelberg leader and has implemented a mechanism that ensures perfect compliance with the cartel agreement. $^{3}$

Existing leadership models are not concerned with antitrust policy and, accordingly, do not include an antitrust authority. Therefore, we introduce a leadership model with a welfare maximizing antitrust authority that tries to deter firms from becoming cartel members. The authority can decide on its own investigative effort, on the appropriate size of the fine that detected cartels must pay, and on the discount offered to testifying firms (leniency program).

In our leadership model, a more aggressive antitrust policy reduces the size of the cartel and increases the number of fringe firms. However, increasing the policy's aggressiveness is not costless for society. This cost must be considered in the design of an optimal antitrust policy. We employ a three-stage game to derive such a policy. In the first stage, the antitrust authority decides on its optimal policy. In the second stage, each of the firms decides on its status (cartel member or fringe firm). In the third stage, all firms determine their optimal output quantities.

The markets in which cartels operate are not uniform and they change over time. For example, stronger demand may increase the market volume and/or new producers may enter the market. Should the antitrust authority react to these changes by an expansion

\footnotetext{
1 EC (2010, paras. 6, 93, 122, 142, 424, 533), EC (2011, p. 1).

2 EC (2003, paras. 1, 36-40, 81-89, 279, 356).

3 This perfect compliance is often denoted as cartel sustainability. The issue of imperfect compliance is usually analyzed in the so-called supergame approach.
} 
or reduction of its three policy instruments (effort, fine, discount)? Should all three instruments change in the same direction or does it make sense to alter two instruments in one direction and the third in the opposite direction? With the comparative statics of our model we can tackle such issues. The analysis reveals that both, the optimal force and the optimal mix of the antitrust authority's policy depend on market characteristics such as the efficiency of the antitrust authority's operations, the public respect for the rule of law, the ethical standards of the firms' managers, the market volume, and the number of firms operating on the market. We show that minor expansions of the market volume allow for a reduction of all three policy instruments, while the optimal response to large expansions of the market volume is a more aggressive policy that induces one or more cartel members to become fringe firms. The same policy implications arise when additional firms enter the market.

This paper proceeds as follows. Section 2 surveys the related literature. In Sect. 3 we introduce our model and discuss its assumptions. Section 4 is devoted to the derivation of the optimal antitrust policy. Section 5 discusses the underlying economics and the resulting policy implications. Concluding remarks are offered in Sect. 6.

\section{Related literature}

Most of the existing literature either neglects the issue of an antitrust policy or precludes fringe firms. A notable exception is Bos and Harrington (2015, p. 135). They propose a supergame framework with fringe firms and an exogenously given antitrust policy and investigate the impact of that policy on the properties of the cartel and the fringe. Their analysis confirms that antitrust policies affect the stability of cartels. At the same time, the authors concede that even with the exogenously given antitrust policy "the relationship between antitrust enforcement and cartel size is too complex for us to provide specific guidance for enforcement policies (p. 148)".

To derive appropriate antitrust enforcement policies, the present paper explores a completely different route. It revives the leadership approach and augments it with an endogenously derived antitrust policy. The leadership approach was once the backbone of stability analysis. In the price leadership model developed by d'Aspremont et al. (1983) the cartel is the Stackelberg price leader. The fringe firms take the leader's price as given and set their quantities such that price equals marginal cost. The price leadership model with its perfectly competitive fringe might fit industries with a large number of competing firms. In the two cartel cases described in the introduction, the number of fringe firms was six and two, respectively. Furthermore, the cartel agreement focused on admissible quantities. Such a situation is better described by a special variant of a framework that Daughety (1990) introduced to analyze the welfare effects of mergers. This special variant is the quantity leadership model advocated by Martin (1990) and Shaffer (1995). The cartel is the Stackelberg quantity leader and the fringe firms are in Cournot competition with respect to the residual demand. The present paper builds on this oligopoly framework.

Leadership models have inspired additional work on the conditions required for the successful formation and stability of cartels. For example, Donsimoni (1985), Donsimoni et al. (1986) and Prokop (1999) utilize the price leadership model, whereas 
studies by Lofaro (1999), Konishi and Lin (1999) and Zu et al. (2012) are based on the quantity leadership model.

Antitrust policy is not an issue in either type of leadership model. Instead, these studies focus on the formal conditions for the existence and uniqueness of a stable cartel. The present study combines the quantity leadership model with an active antitrust authority that wants to maximize social welfare.

\section{Model}

\subsection{Three-stage antitrust game}

Our model is a three-stage game with a finite integer number of $n \geq 2$ identical firms and an antitrust authority. First, the antitrust authority chooses its policy, taking into account the reactions of the $n$ firms. Then, given the implemented antitrust policy, each of the $n$ firms decides whether it wants to become a fringe firm or a member of the cartel. The resulting number of fringe firms is denoted by $n_{F}$. The remaining $\left(n-n_{F}\right)$ firms form the cartel. In their choice between fringe and cartel the firms take into account the resulting equilibrium output quantities and the associated profits. Both are determined in the third stage of our antitrust game.

In that final stage, all $n$ firms produce the same homogeneous good and have the same constant marginal cost equal to $c$. The inverse demand function is $P=a-b Q$, where $P$ is the market price, $Q$ is the aggregate quantity produced, and $a$ and $b$ are positive constants. Without loss of generality, we can choose the units of the good and the currency such that $(a-c)=1$ and $b=1$. Therefore, the market volume, $(a-c) / b$, is normalized to 1 .

The cartel's sustainability is not an issue. It is assumed that the $\left(n-n_{F}\right)$ members of the cartel act as one company and collectively determine their profit maximizing joint output $Q_{K}$. Afterwards, each fringe firm determines its profit maximizing output $q_{F}$. In other words, the cartel acts as a Stackelberg leader, while the group of fringe firms is the Stackelberg follower. ${ }^{4}$ If the cartel shrinks to one firm $\left(n-n_{F}=1\right)$, this firm will no longer represent an illegal cartel, but will become a legal Stackelberg leader. Since that firm would never want to give up that position, we know that $n_{F} \leq n-1$. Each fringe firm considers both the cartel's output, $Q_{K}$, and the aggregate output of the other fringe firms, $Q_{-F}$, as given. Therefore, the output of each fringe firm, $q_{F}$, is determined by the Cournot-Nash equilibrium concept.

The antitrust authority's policy is implemented before the $n$ firms decide on their cartel membership and their output quantities. Three policy instruments are available to the authority. The first instrument is the fine $f \geq 0$ that the members of a detected cartel must pay. The second instrument is the expected discount $d \in[0,1)$ offered

\footnotetext{
${ }^{4}$ In equilibrium, the cartel always produces more than half of the complete output. Therefore, assigning the role of the Stackelberg leader to the cartel is a reasonable feature of the quantity leadership model. As an additional justification, Shaffer (1995, pp. 348-349) points out that the cartel benefits from the Stackelberg sequence and, therefore, may want to impose its will on the fringe firms. Huck et al. (2007) provide some experimental evidence that firms that cooperate in a binding manner show leadership behavior, whereas the remaining firms exhibit follower behavior. For additional references that support the leadership role of perfectly colluding firms see Brito and Catalão-Lopes (2011, pp. 3-4).
} 
to some or all cartel firms that inform the authority about the cartel. Accordingly, $f(1-d)$ is the average fine of the members of a detected cartel. The third policy instrument is the authority's own investigative effort, $e \geq 0$.

If a cartel exists $\left(n-n_{F} \geq 2\right)$, it is detected with some probability $p \in[0,1]$. Therefore, $p f(1-d)$ is the expected fine of each member of the cartel. The probability of detection, $p$, depends on the antitrust authority's policy. More specifically, we assume that

$$
p=h(e, f, d) g\left(n-n_{F}\right) .
$$

The factor $h(e, f, d) \in[0,1]$ captures the impact of the authority's antitrust policy. We assume that $h(e, f, d)$ is a continuous concave function that approaches 1 from below and has positive first order derivatives. The second factor, $g\left(n-n_{F}\right) \in[0,1]$, takes care of the fact that larger cartels are more likely to be detected than smaller ones. We assume that $g(1)=0$ and that $g\left(n-n_{F}\right)$ is a continuous concave function approaching 1 from below. A detailed justification for these assumptions is provided in Sect. 3.2.

Our model recognizes that the implementation of an antitrust policy is not costless. Following the law enforcement literature initiated by Becker (1968), we capture this cost by a continuous social cost function, $s(e, f, d)$, with positive first order partial derivatives.

The objective of the antitrust authority is to implement a policy $(e, f, d)$ that maximizes welfare. This policy is denoted as the optimal antitrust policy. Welfare does not depend on the budgetary effects of the fines and discounts, because these are of a purely redistributional nature. Therefore, welfare is defined here as the sum of consumer and producer rent minus the social cost, $s(e, f, d)$, caused by the antitrust policy. ${ }^{5}$

Section 3.2 provides an elaborate discussion of the assumptions relating to Eq. (1) and to the social cost function $s(e, f, d)$. Therefore, readers that are primarily interested in the solution of the three-stage game can skip over Sect. 3.2 and directly proceed to Sect. 4 .

\subsection{Discussion of some assumptions}

In practice, fines are often linked to revenues or to profits. However, for algebraic simplicity, we assume that the fine, $f$, is lump-sum.

There is ample evidence that leniency programs increase the probability of detecting cartels (e.g., Aubert et al. 2006, p. 1242; Brenner 2009, pp. 642-644). In anticipation of being detected, cartel firms may apply for leniency by providing evidence of a cartel agreement. Furthermore, even if cartel members consider it unlikely that the antitrust authority will discover anything, they may worry that some fellow member will apply for leniency and, because of that worry, apply themselves. Harrington (2013, pp. 2-3) denotes these two effects as "prosecution effect" and "preemption" effect, respectively. The policy variables $f$ and $d$ in $h(e, f, d)$ capture these effects. We define the expected discount by $d=r \mu \in[0,1)$, with $r \geq 0$ denoting the percentage by

\footnotetext{
5 Wilson (2019) and Albæk (2013) present some explanations why antitrust authorities such as the U.S. Federal Trade Commission and the European Commission focus on consumer rent and tend to neglect producer rent. A compact discussion of these issues can be found in Motta (2004, pp. 19-22).
} 
which the fine of an eligible and cooperating cartel member is reduced, and $\mu \in[0,1]$ denoting the share of cartel members eligible for that reduction. ${ }^{6}$ An expansion of eligibility, $\mu$, or an increase in the percentage $r$ by which the fine of an eligible cartel member is reduced, strengthens the preemptive effect of discounts. However, it lowers the average fine of the members of a detected cartel, weakening the prosecution effect. We assume that the former effect dominates the latter effect, that is, $\partial h / \partial d>0$. Our specification allows for a percentage $r>1$. For plausibility reasons, however, we restrict the domain of $d=r \mu$ to the interval $[0,1){ }^{7}$

A positive effort, $e$, is necessary to turn the fine and the leniency program into effective instruments. Without any effort on the side of the antitrust authority, the prosecution effect and the preemption effect do not exist, regardless of the size of the cartel and the size of the fine. Therefore, the case $e=0$ must give $p=0$, which requires that $h(0, f, d)=0$. When a detected cartel never pays a fine $(f=0)$, the investigative staff is likely to be demoralized and its effort may become completely ineffective, that is, $h(e, 0, d)=0$. If the fine for detected cartels is positive, the antitrust authority must be able to detect an existing cartel through its own investigative effort $e$. Therefore, we assume that $h(e, f, 0)>0$, when $e>0$ and $f>0$.

The assumption $g(1)=0$ ensures that a "cartel" with only one member cannot be detected, because this member does not form an illegal cartel, but merely represents a legal Stackelberg leader.

The function $s(e, f, d)$ represents the social cost arising from the three antitrust policy instruments. Obviously, if society desires a larger effort, $e$, it must provide the resources necessary to hire more and better staff and to purchase a more effective system. Less obvious is the social cost arising from the fine $f$. The antitrust authority has a strong incentive to choose very large fines, because this reduces the expected profits from cartel membership. Excessive fines, however, induce a social cost, because they violate the principle of proportional justice and may increase the risk of convicting innocent firms (e.g., Allain et al. 2015). The discount, $d$, causes similar social costs. The public may dislike the idea that testifying firms that have broken the law can get away with a discount or, even worse, are rewarded. Lenient treatment of guilty firms may undermine a general respect for the law and may encourage unlawful behavior.

\section{Solution}

We will solve our three-stage game by backward induction, starting with the derivation of the profit maximizing quantity reactions, $q_{F}$ and $Q_{K}$, to each given antitrust policy, $(e, f, d)$, and number of fringe firms, $n_{F}$ (Sect. 4.1). Then, to each given antitrust policy, $(e, f, d)$, we derive the equilibrium number of $n_{F}$, that is, the profit maximizing status decisions (fringe or cartel) of the $n$ firms (Sect. 4.2). To this end, we exploit the previously derived quantity reactions, $q_{F}$ and $Q_{K}$, and the concept of stability.

\footnotetext{
6 Suppose that the cartel is detected. If $\mu=0.1$ and the number of cartel members is $n-n_{F}=10$, then exactly one member is randomly drawn. This member is regarded as a cooperating firm and receives the reduction $r$. If $\mu=0.1$ and $n-n_{F}=5$, again one member is randomly drawn and that member has a $50 \%$ chance of being regarded as a cooperating firm.

7 Otherwise, the members of a detected cartel, on average, receive a reward instead of a fine: $f(1-d) \leq 0$.
} 
Finally, given the equilibrium reactions of the $n$ firms (status and output quantity), we derive the optimal antitrust policy (Sect. 4.3).

\subsection{Third stage: determining the output quantities}

In the presence of a given antitrust policy, $(e, f, d)$, and a given number of fringe firms, $n_{F} \in(0, \ldots, n-1)$, there is a given expected fine, $p f(1-d)$. This fine can be interpreted as a fixed cost of the cartel members and, therefore, does not affect their profit maximizing behavior. The resulting equilibrium output of the cartel (Stackelberg leader) is

$$
Q_{K}=\frac{1}{2}
$$

while each fringe firm produces

$$
q_{F}=\frac{1}{2\left(n_{F}+1\right)} .
$$

Therefore, total output is

$$
Q=Q_{K}+n_{F} q_{F}=\frac{2 n_{F}+1}{2 n_{F}+2} .
$$

Note that total output is independent of the total number of firms, $n$, and the number of cartel members, $\left(n-n_{F}\right)$. Instead, total output exclusively depends on the number of fringe firms, $n_{F}$. If an antitrust policy wants to increase total output, it must induce members of the cartel to join the fringe.

The profit of each fringe firm is

$$
\pi_{F}\left(n_{F}\right)=\frac{1}{4\left(n_{F}+1\right)^{2}}
$$

while each cartel member receives the expected profit

$$
E\left[\pi_{K}\left(n_{F}\right)\right]=\frac{1}{4\left(n_{F}+1\right)\left(n-n_{F}\right)}-p f(1-d) .
$$

This finding reveals that the expected fine, $p f(1-d)$, is the antitrust authority's only instrument to discourage firms from collusion.

\subsection{Second stage: choosing the status}

At this stage, the $n$ firms decide whether they want to become a fringe firm or a member of the cartel. In their decision, they take the policy $(e, f, d)$ as given and they anticipate the quantity reactions (2) and (3) and the associated profits (5) and (6). 
Suppose that a member of the cartel is presented with an offer to join the $n_{F}$ fringe firms. If and only if

$$
E\left[\pi_{K}\left(n_{F}\right)\right]>\pi_{F}\left(n_{F}+1\right),
$$

the firm rejects the offer. If all cartel members reject the offer, the cartel is denoted as internally stable. ${ }^{8}$ The cartel is externally stable, if each of the $n_{F}$ fringe firms rejects the offer to become a member of the cartel. This rejection arises, if and only if

$$
E\left[\pi_{K}\left(n_{F}-1\right)\right] \leq \pi_{F}\left(n_{F}\right) .
$$

A stable cartel is a cartel that is internally and externally stable. ${ }^{9}$

Our model determines the final status of a firm (cartel or fringe) using the following random process. First, each of the $n$ firms is randomly assigned its status. Then one firm is randomly drawn and given the opportunity to change its status. If the firm is a member of the cartel and if (7) is violated, the firm decides to become a fringe firm. Since all cartel members are identical, the decision is independent of which cartel member is drawn. If, instead, a fringe firm is drawn and condition (8) is violated, this firm decides to enter the cartel. Again, the decision is independent of which fringe firm is drawn. Next, another (or the same) firm is randomly drawn and allowed to change its status. This random process is continued until two consecutive draws occur in which the two firms drawn have different statuses and both decide to keep their status. After these two decisions the random process terminates, because all fringe firms are identical and all cartel members are identical and, therefore, in all additional random draws no firm would want to change its status.

For the characterization of the equilibrium solution it is useful to define the "force", $A$, of the given policy $(e, f, d)$ by the following expression:

$$
A:=h(e, f, d) f(1-d) \geq 0 .
$$

The value of $A$ depends on the policy instruments $e, f$ and $d$, but not on $n$ and $n_{F}$. In Sect. 3.2 it was explained that any antitrust policy with $e=0$ or $f=0$ leads to $h(e, f, d)=0$ and, therefore, to $A=0$ and $p=0$. Therefore, such a policy completely eliminates the possibility of detecting an operating cartel. We denote such policies as passive antitrust policies. Increases in the effort, $e$, and the fine, $f$, raise the value of $A$. The impact of the discount $d$ on the value of $A$ is ambiguous, since it increases the value of the factor $h(e, f, d)$ and, therefore, the probability of detection, $p$, but lowers the average fine of the members of a detected cartel, $f(1-d)$. Since $d$ was restricted to values smaller than $1, A$ cannot be negative.

The profits (5) and (6) imply that an all-inclusive cartel $\left(n_{F}=0\right)$ is internally stable, if and only if

$$
A<\frac{1}{4}\left(\frac{1}{n}-\frac{1}{4}\right) .
$$

\footnotetext{
${ }^{8}$ In the original definition given by d'Aspremont et al. (1983, p. 21) and many subsequent papers a weakly larger profit is sufficient to reject the offer.

9 Thoron (1998) demonstrates that the internal and external stability concepts merely reproduce a Nash equilibrium of a participation game.
} 
For $n \geq 4$, the right-hand side would be non-positive, while $A$ is non-negative. Therefore, an all-inclusive cartel with more than three members cannot be internally stable, even when $A=0$. At least one member of the cartel would decide to change its status. For $n=3$ or $n=2$, however, an all-inclusive internally stable cartel is conceivable. For such cartels, the external stability condition is redundant, since no firm is left over that could enter the cartel.

Furthermore, we introduce the following "threshold variable":

$$
T\left(n_{F}\right):=\frac{n_{F}\left(2 n_{F}+1-n\right)+1}{4 n_{F}\left(n-n_{F}+1\right)\left(n_{F}+1\right)^{2} g\left(n-n_{F}+1\right)} .
$$

It is independent of the policy $(e, f, d)$. In Auer and Pham (2020, Lemma 1, Appendix, pp. 16-17) it is shown that $\partial T\left(n_{F}\right) / \partial n_{F}>0$.

Theorem 1 Given some antitrust policy $(e, f, d)$ and the quantity reactions (2) and (3), the random process that determines a firm's status leads to a unique equilibrium $n_{F}$-value. Policies that satisfy condition (10) lead to $n_{F}=0$. For all other policies, the equilibrium value of $n_{F}$ is given by

$$
T\left(n_{F}\right) \leq A<T\left(n_{F}+1\right) .
$$

Proof See Auer and Pham (2020, Appendix, p. 17).

Theorem 1 determines the size of the stable cartel for each policy, $(e, f, d)$. For example, a policy with the force $A=T\left(n_{F}\right)$ leads to a stable cartel with $\left(n-n_{F}\right)$ members. Since $\partial T\left(n_{F}\right) / \partial n_{F}>0$, an increase in the equilibrium $n_{F}$-value (that is, a reduction of the cartel's size) requires an increase in the policy's force, $A$. Whether such an increase is desirable, is to be examined in the first stage of the antitrust game.

\subsection{First stage: determining the antitrust policy}

The sum of consumer and producer rent is equal to $\left(Q-0.5 Q^{2}\right)$, where the value of $Q$ is defined by (4). Subtracting the social cost, $s(e, f, d)$, yields the following welfare function:

$$
W(e, f, d)=\frac{\left(2 n_{F}+1\right)\left(2 n_{F}+3\right)}{8\left(n_{F}+1\right)^{2}}-s(e, f, d) .
$$

The antitrust authority chooses its policy, $(e, f, d)$, such that welfare, $W(e, f, d)$, is maximized. This policy is denoted as the authority's optimal antitrust policy, $\left(e^{*}, f^{*}, d^{*}\right)$. In the derivation of this policy, the authority anticipates the equilibrium $n_{F}$-value (determined by Theorem 1 ) and the corresponding quantity reactions (2) and (3).

Relationship (12) implies that for passive antitrust policies the condition for stability becomes

$$
T\left(n_{F}\right) \leq 0<T\left(n_{F}+1\right) .
$$

Only one $n_{F}$-value exists that satisfies this condition. We denote this value by $n_{F}^{\min }$, because an active antitrust policy ( $e>0$ and $f>0$ ) would lead to $n_{F}$-values that are 
at least as large as $n_{F}^{\min }$ and, therefore, to cartels that are never larger than $\left(n-n_{F}^{\min }\right)$. Thus, we can confine our search for the optimal antitrust policy to those policies $(e, f, d)$ that lead to $n_{F} \in\left(n_{F}^{\min }, \ldots, n-1\right)$.

To find the optimal antitrust policy $\left(e^{*}, f^{*}, d^{*}\right)$, we pursue a three-step procedure. First, we find $n_{F}^{\min }$. Then, we derive for each given $n_{F} \in\left(n_{F}^{\min }, \ldots, n-1\right)$ the antitrust policy $\left(e_{n_{F}}^{*}, f_{n_{F}}^{*}, d_{n_{F}}^{*}\right)$ that minimizes the social cost, $s(e, f, d)$. Finally, we compute the resulting welfare for each of these cost minimizing antitrust policies. The policy that generates the largest welfare is the unique optimal antitrust policy $\left(e^{*}, f^{*}, d^{*}\right)$. In the following, we describe these three steps in more detail.

Finding $n_{\boldsymbol{F}}^{\min }$ (step 1): For $n=2$ or $n=3$, we get $n_{F}^{\min }=0$. When $n>3$ and a passive antitrust policy is chosen, the number $n_{F}^{\min }$ is the smallest $n_{F}$-value that satisfies the left-hand side inequality of (14). Using (11), this inequality simplifies to $\left(n-n_{F}\right) \geq n_{F}+1+1 / n_{F}$. Therefore, $n_{F}^{\min }$ is the largest integer for which the condition $\left(n-n_{F}^{\min }\right) \geq\left(n_{F}^{\min }+2\right)$ is satisfied. Rearranging this condition gives $n_{F}^{\min } \leq(n-2) / 2 .{ }^{10}$ Therefore,

$$
n_{F}^{\min }=\left\{\begin{array}{l}
(n-2) / 2 \text { for even } n \\
(n-3) / 2 \text { for uneven } n
\end{array}\right.
$$

The antitrust authority can restrict its search for the optimal antitrust policy $\left(e^{*}, f^{*}, d^{*}\right)$ to policies that lead to $n_{F} \geq n_{F}^{\min }$, where $n_{F}^{\min }$ is defined by (15).

Computing the cost minimizing policies (step 2) Among all antitrust policies leading to a stable cartel with $\left(n-n_{F}^{\min }\right)$ members, the passive policy $(e, f, d)=(0,0,0)$ is the cost minimizing policy $\left(e_{n_{F}^{*}}^{*}, f_{n_{F}^{\min }}^{*}, d_{n_{F}^{\min }}^{*}\right)$.

Suppose that the antitrust authority wants to raise the number of fringe firms above $n_{F}^{\min }$. This requires an active antitrust policy, that is, a policy with $e>0, f>0$ and $d \geq 0$. From condition (12) we know that an active antitrust policy pursuing a cartel with $\left(n-n_{F}\right)$ members must be such that the resulting $A$-value defined by (9) falls into the interval $\left[T\left(n_{F}\right), T\left(n_{F}+1\right)\right)$. An infinite number of active policies exist that satisfy this condition. All of these policies lead to the same given $n_{F}$-value and, therefore, to the same quantity $Q$. Thus, they all yield the same consumer rent and producer rent. However, the social cost varies. Therefore, the authority should choose the policy that causes the lowest social cost, $s(e, f, d)$. Since $\partial s / \partial d>0$, a welfare maximizing antitrust authority will always decide for a $d$-value that satisfies the condition $\partial A / \partial d>0$. This implies that lower $A$-values allow for lower values of $e, f$ and $d$. In other words, lower $A$-values reduce the social cost, $s(e, f, d)$.

Therefore, for each given $n_{F}$-value, the antitrust authority should opt for a policy the force of which, $A$, reaches the lower bound of its admissible interval defined by (12):

$$
A=T\left(n_{F}\right) .
$$

Choosing a force $A$ slightly below $T\left(n_{F}\right)$ would make a cartel with $\left(n-n_{F}\right)$ members externally instable and its size would increase to $\left(n-n_{F}+1\right)$. Therefore, Equation

10 This is just a reformulation of Shaffer's (1995, p. 746) Proposition 4. 
(16) defines the smallest possible force, $A$, that caps the cartel size at $\left(n-n_{F}\right)$. We denote condition (16) as the efficacy condition.

An infinite number of policies $(e, f, d)$ satisfy the efficacy condition (16). Among these policies, the authority should choose the one that causes the lowest social cost, $s(e, f, d)$. For given $n_{F}$, this cost minimization problem can be written in the following form:

$$
\min _{e, f, d} s(e, f, d) \quad \text { subject to } A=T\left(n_{F}\right) .
$$

The unique solution to this cost minimization problem is denoted by $\left(e_{n_{F}}^{*}, f_{n_{F}}^{*}, d_{n_{F}}^{*}\right)$. We know that this solution is characterized by $e>0$ and $f>0$. An interior solution would also require that $d>0$.

To keep the model analytically tractable, we assume that the two factors of the probability of detection, $p$, defined by Equation (1) are given by

$$
g\left(n-n_{F}\right)=\frac{n-n_{F}-1}{n-n_{F}}
$$

and

$$
h(e, f, d)=w(e) \cdot k(d) \cdot m(f),
$$

where

$$
\begin{aligned}
w(e) & =\frac{e}{e+1} \\
k(d) & =\frac{d+\rho}{d+\rho+1} \quad(\rho>0) \\
m(f) & =\frac{f}{f+1} .
\end{aligned}
$$

This specification is fully consistent with the postulated properties of $g\left(n-n_{F}\right)$ and $h(e, f, d)$ discussed in Sects. 3.1 and 3.2.

Furthermore, we assume that the continuous social cost function is

$$
s(e, f, d)=s(z) \quad \text { with } \quad z=\alpha e+\beta f m(f)+\gamma d \quad \text { and } \quad \partial s / \partial z>0 .
$$

The parameters $\alpha, \beta$ and $\gamma$ can be interpreted as the marginal effects of the respective policy instrument on the social cost variable $z .^{11}$

The specifications (18) to (23) imply that a unique solution arises (though not necessarily an interior solution). ${ }^{12}$ To characterize the cost minimizing policy $\left(e_{n_{F}}^{*}, f_{n_{F}}^{*}, d_{n_{F}}^{*}\right)$, we make use of the following definitions:

$$
\mathcal{E}:=\frac{T\left(n_{F}\right)}{k(d)(1-d)}
$$

\footnotetext{
11 For reasons of analytical simplicity, we use the function $\beta f m(f)$ instead of the simple linear function $\beta f$. Since $\lim _{f \rightarrow \infty} m(f)=1$, the function $\beta f m(f)$ closely approximates the function $\beta f$.

12 Uniqueness merely requires that in $e$ - $f-d$-space the plane corresponding to the efficacy condition (16) and to a given $n_{F}$-value is "more convex" than the isocost-planes of the applied social cost function.
} 


$$
\begin{aligned}
\mathcal{F} & :=\mathcal{E}+\left(\frac{\alpha}{\beta} \mathcal{E}\right)^{1 / 2} \\
\mathcal{D} & :=-\frac{\partial \mathcal{E}}{\partial d}\left[\left(\frac{\alpha \beta}{\mathcal{E}}\right)^{1 / 2}+\beta\right] .
\end{aligned}
$$

The three terms $\mathcal{E}, \mathcal{F}$ and $\mathcal{D}$ depend on $d$, but not on $e$ and $f$.

Theorem 2 For each $n_{F} \in\left(n_{F}^{\min }+1, \ldots, n-1\right)$, the unique cost minimizing policy that leads to a stable cartel with $\left(n-n_{F}\right)$ members, is

$$
\begin{aligned}
e_{n_{F}}^{*} & =\left(\frac{\beta}{\alpha} \mathcal{E}\right)^{1 / 2} \\
f_{n_{F}}^{*} & =\frac{1}{2}\left[\mathcal{F}+\left(\mathcal{F}^{2}+4 \mathcal{F}\right)^{1 / 2}\right] .
\end{aligned}
$$

If $d$ is endogenous, an interior solution, $d_{n_{F}}^{*}>0$, must satisfy the condition

$$
\mathcal{D}=\gamma
$$

Proof See Auer and Pham (2020, Appendix, pp. 20-21).

For a given cartel size, $\left(n-n_{F}\right)$, Eqs. (27) to (29) of Theorem 2 specify the cost minimizing policy $\left(e_{n_{F}}^{*}, f_{n_{F}}^{*}, d_{n_{F}}^{*}\right)$, such that the efficacy condition (16), $A=T\left(n_{F}\right)$, is satisfied.

An increase in $e$ or $f$ raises the antitrust policy's force, $A=h(e, f, d) f(1-d)$. The effort, $e$, exerts its positive influence only via the "probability factor" $h(e, f, d)$, while the fine, $f$, exerts its positive influence via both, the probability factor $h(e, f, d)$ and the average fine $f(1-d)$.

The third policy variable is the expected discount, $d$. As was true for $e$ and $f$, an increase in $d$ increases the probability factor $h(e, f, d)$. However, an increase in $d$ also reduces the average fine $f(1-d)$ and, therefore, counteracts the increase in $h(e, f, d)$. As a consequence, an increase in $d$ can make sense only if it has a strong positive effect on $h(e, f, d)$. This requires that the original $d$-value was sufficiently small. Since the right-hand side of condition (29) and the expression in square brackets in Eq. (26) are positive, the inequality $\partial \mathcal{E} / \partial d_{n_{F}}^{*}<0$ is a necessary condition for a cost efficient positive discount $d_{n_{F}}^{*}$.

Auer and Pham (2020, Lemma 2, Appendix, pp. 18-19) show that $\partial \mathcal{E} / \partial d<0$, if and only if $(d+\rho)^{2}+2 d+\rho<1$. For $\rho \geq 0.61803$, this inequality is never satisfied. In other words, if $\rho \geq 0.61803$ the cost minimizing value of $d$ is $d_{n_{F}}^{*}=0$ and Eq. (29) of Theorem 2 is redundant. The cost minimizing values $e_{n_{F}}^{*}$ and $f_{n_{F}}^{*}$ are obtained from Eqs. (27) and (28). If $\rho<0.61803$ and, at the same time, $\gamma$ is not too large, the value $d_{n_{F}}^{*}$ satisfying condition (29) is positive. Inserting this cost minimizing value $d_{n_{F}}^{*}$ in 
(24) to (28), yields the cost minimizing values $e_{n_{F}}^{*}$ and $f_{n_{F}}^{*}$. For each given $n_{F}$, the cost minimizing policy $\left(e_{n_{F}}^{*}, f_{n_{F}}^{*}, d_{n_{F}}^{*}\right)$ is derived in this way. ${ }^{13}$

Selecting the optimal antitrust policy (step 3) If the expected discount is exogenously given, $d=\bar{d}$, we insert $n_{F}=n_{F}^{\min }$ and the passive policy $(0,0, \bar{d})$ in the welfare function (13) and compute the corresponding welfare level. Then we compile the welfare levels arising from active policies. To this end, we insert $\bar{d},(23),(27)$ and (28) in the welfare function (13) and maximize this expression with respect to $n_{F}$. We obtain the optimal fringe size, $n_{F}^{*}$, the corresponding policy $\left(e^{*}, f^{*}, \bar{d}\right)$, and the resulting welfare. The policy $\left(e^{*}, f^{*}, \bar{d}\right)$ is implemented, if the associated welfare is larger than the welfare arising from the passive policy $(0,0, \bar{d})$.

When $d$ is endogenous, we start by inserting $n_{F}=n_{F}^{\min }$ and the passive policy $(e, f, d)=(0,0,0)$ in welfare function (13) and compute the resulting welfare level. Then we consider the cost minimizing active antitrust policies $\left(e_{n_{F}}^{*}, f_{n_{F}}^{*}, d_{n_{F}}^{*}\right)$. The welfare levels corresponding to each integer $n_{F} \in\left(n_{F}^{\min }+1, \ldots, n-1\right)$ are calculated. For this purpose we insert each of these $n_{F}$-values together with its corresponding cost minimizing policy $\left(e_{n_{F}}^{*}, f_{n_{F}}^{*}, d_{n_{F}}^{*}\right)$ in the welfare function (13). We get a set of welfare levels. From this set we select the maximum value. If this welfare is larger than the one generated by the passive policy, the corresponding number of fringe firms is the optimal fringe size $n_{F}^{*}$. The cost minimizing antitrust policy leading to the stable cartel with $\left(n-n_{F}^{*}\right)$ members is the unique optimal antitrust policy $\left(e^{*}, f^{*}, d^{*}\right)$.

\section{Further analysis and policy recommendations}

To derive important economic implications from Theorem 2, we analyze how changes in the parameter values affect the optimal antitrust policy $\left(e^{*}, f^{*}, d^{*}\right)$. We begin the analysis with small parameter changes that do not affect the optimal number of fringe firms, $n_{F}^{*}$. Afterwards, larger parameter changes are considered that alter $n_{F}^{*}$. Only interior solutions $\left(d^{*}>0\right)$ are discussed.

The force of the original optimal antitrust policy, $\left(e^{*}, f^{*}, d^{*}\right)$, is denoted by $A^{*}$ and the corresponding threshold by $T\left(n_{F}^{*}\right)$. We analyze changes in the social cost parameters $(\alpha, \beta, \gamma)$, the discount parameter $(\rho)$, the market volume parameters $(a, b, c)$, and the number of firms $(n)$. Changes in the parameters $\alpha, \beta, \gamma$ and $\rho$ do not alter the threshold $T\left(n_{F}^{*}\right)$. They primarily affect the relative cost-effectiveness of the three antitrust policy instruments. By contrast, changes in the parameters $a, b, c$ and $n$ change the threshold $T\left(n_{F}^{*}\right)$ and, therefore, primarily affect the overall cost-effectiveness of antitrust policy.

Our findings can be interpreted in two different ways. Obviously, they show how the antitrust authority should adjust its policy to changes that occur in some given market. However, they also describe how differences between two markets should be

13 In many countries, the antitrust authorities are not completely free to determine their policy $(e, f, d)$, but are restricted by legal regulations on the fine, $f$, and/or the expected discount, $d$. For example, if the expected discount is legally fixed at $d=\bar{d}$, Eq. (29) is redundant. Instead, the value $\bar{d}$ is inserted in Eq. (24). 
Table 1 Comparative statics of optimal antitrust policy for given $n_{F}^{*}$ ("+" indicates a positive and "-_" a negative derivative)

\begin{tabular}{llll}
\hline Parameter & Effort $e^{*}$ & Fine $f^{*}$ & Exp. discount $d^{*}$ \\
\hline$\alpha$ & - & + & + \\
$\beta$ & + & - & + \\
$\gamma$ & + & + & - \\
$\rho$ & - & - & - \\
$a$ & + & + & + \\
$b$ & - & - & - \\
$c$ & - & - & - \\
$n$ & - & - & - \\
\hline
\end{tabular}

reflected in the corresponding optimal antitrust policies. After the presentation of the formal results (Theorem 3), we provide a brief intuitive elucidation of these results.

Theorem 3 Marginal changes in the social cost parameters $(\alpha, \beta, \gamma)$, the discount parameter $(\rho)$, the market volume parameters $(a, b, c)$, or the number of firms $(n)$, affect the optimal antitrust policy $\left(e^{*}, f^{*}, d^{*}\right)$, but not the optimal number of fringe firms, $n_{F}^{*}$. The individual effects of the parameter changes are listed in Table 1.

Proof See Auer and Pham (2020, Appendix, pp. 24-25).

Social cost parameters $\alpha, \beta$ and $\gamma$ : The larger the parameter $\alpha$, the more resources the antitrust authority needs to achieve a given level of effort $e$. The parameters $\beta$ and $\gamma$ measure the damage to the rule of law when disproportionate fines are imposed, innocent firms are prosecuted, or discounts are granted to guilty firms. A small change in $\alpha, \beta$, or $\gamma$ does not affect the threshold $T\left(n_{F}^{*}\right)$. Therefore, the new policy must preserve the original policy's force, $A^{*}$.

Suppose that parameter $\alpha$ increases (e.g., the antitrust authority must pay higher wages to attract or retain qualified personnel). We know that an optimal antitrust policy, $\left(e^{*}, f^{*}, d^{*}\right)$, ensures that marginal changes to any pair of policy instruments (e.g., $e$ and $f$ ) consistent with the efficacy condition, lead to changes in the social cost that exactly offset each other. An increase in $\alpha$ raises the relative cost of effort $e$ and reduces the relative cost of the fine $f$ and the expected discount $d$. More specifically, to preserve the original policy's force, $A^{*}$, the role of $e$ within the probability factor $h(e, f, d)$ must be reduced in favor of $f$ and $d$. Furthermore, the role of the probability factor $h(e, f, d)$ must be downsized in favor of the factor $f(1-d)$. The latter requires an increase in $f$ and a reduction of $d$. Theorem 3 reveals that the overall effect on $d$ is positive.

A small increase in $\beta$ (e.g., stronger public dislike for disproportionate penalties) strengthens the role of $e$ and $d$ and weakens the role of $f$ within the probability factor $h(e, f, d)$ and the factor $f(1-d)$. The latter would require a reduction of $f$ and/or $d$. Again, Theorem 3 reveals that the overall effect on $d$ is positive.

A small increase in $\gamma$ (e.g., stronger erosion of the respect for the law when guilty firms get away with reduced fines) raises the cost of the expected discount relative to the cost of the effort and the fine. Within the factors $h(e, f, d)$ and $f(1-d)$ the role of $d$ must be reduced in favor of $e$ and $f$. 
Discount parameter $\rho$ : The parameter $\rho$ indicates the independence of the antitrust policy's efficacy from the existence and size of the leniency program (expected discount $d^{*}$ ). As was pointed out earlier, for $\rho \geq 0.61803$ no leniency program should be installed $\left(d^{*}=0\right)$. Here we consider smaller $\rho$-values such that $d^{*}>0$. A small increase in $\rho$ (e.g., improved ethical standards within the management of the firms) raises the probability factor $h(e, f, d)$ and, therefore, the original policy's force such that $A^{*}>T\left(n_{F}^{*}\right)$. The increase in $A^{*}$ allows for reductions of all three policy instruments, $e^{*}, f^{*}$ and $d^{*}$.

Market volume parameters $a, b$ and $c$ : The model was normalized such that the market volume is $(a-c) / b=1$. How should the antitrust authority react to changes in the market volume? A small increase in $a$ or a small reduction in $c$ or $b$ increase the market volume, the sum of consumer and producer rent and, therefore, the value of $T\left(n_{F}^{*}\right)$ such that $A^{*}<T\left(n_{F}^{*}\right) .{ }^{14}$ To restore the efficacy condition, the policy's force, $A^{*}$, must increase, that is, $e^{*}, f^{*}$ and $d^{*}$ must be raised.

Number of firms $n$ : In dynamic markets, new firms can enter. If they join the cartel, the number of fringe firms, $n_{F}$, remains constant, while $n$ increases. The profits of the fringe firms are not affected by the additional cartel member. This is also true for the aggregate profit of the cartel. However, the profit per cartel member falls and, therefore, the attractiveness of the cartel status also falls. This allows the antitrust authority to lower the values of the three policy variables $e^{*}, f^{*}$ and $d^{*}$, without changing the number of fringe firms.

Next, we discuss large parameter changes that affect the optimal number of fringe firms, $n_{F}^{*}$. Consider again some optimal policy, $\left(e^{*}, f^{*}, d^{*}\right)$, and the corresponding force, $A^{*}$. A sufficient increase in $e, f$ and $d$ and, therefore, of $A$ would induce one of the cartel members to become a fringe firm. This changeover increases the sum of consumer and producer rent by

$$
\frac{2 n_{F}+3}{8\left(n_{F}^{2}+3 n_{F}+2\right)^{2}}>0 .
$$

We denote this beneficial welfare effect as the positive "output effect" of the additional fringe firm. For all positive values of $n_{F}$, the output effect is positive and falling in $n_{F}$. However, the additional fringe firm also causes a negative "cost effect", because the larger values of $e, f$ and $d$ raise the social cost $s(e, f, d)$. Since the original force, $A^{*}$, was optimal, the cost effect would overcompensate the output effect and welfare would fall.

However, after a sufficiently large change in the parameters, the original force $A^{*}$ might be no longer optimal and the output effect may outweigh the cost effect. For example, consider a significant decrease in the social cost parameters $\alpha, \beta$ and $\gamma$. For each given $n_{F}$, the change in the parameters reduces the negative cost effect, while the output effect is unaffected. The same is true when $\rho$ increases. If the reduction of the cost effect is sufficiently strong, the increase in $A$ above the original level $A^{*}$ and the ensuing increase in $n_{F}$ from $n_{F}^{*}$ to $\left(n_{F}^{*}+1\right)$ would be welfare increasing. Theoretically, even a change to $\left(n_{F}^{*}+2\right)$ could be welfare increasing. Note, however,

\footnotetext{
$\overline{14}$ Without the normalization of $(a-c)$ and $b$, the threshold $T\left(n_{F}\right)$ would include the factor $(a-c)^{2} / b$.
} 
that the output effect defined by Eq. (30) is falling in $n_{F}$, while, due to the specification of $h(e, f, d)$, the size of the cost effect tends to increase.

Without the normalization of $(a-c)$ and $b$, Eq. (30) would include the factor $(a-c)^{2} / b$. Therefore, a significant increase in the market volume, $(a-c) / b$, leads to a strong increase in the output effect. However, the value of $T\left(n_{F}\right)$ and, therefore, the required values of the three policy instruments also increase (see Theorem 3 ). Unless the cost function possesses a highly exponential form, the former effect would dominate the latter, such that raising $n_{F}$ to $\left(n_{F}^{*}+1\right)$ would be welfare increasing.

Finally, suppose that new firms enter the market and that all of them join the cartel. Then, $n$ increases, but $n_{F}$ remains constant. From Theorem 3 we know that this parameter change allows for a reduction of all three policy instruments. Therefore, for each given $n_{F}$, the cost effect falls. The output effect, however, remains unchanged, because it depends on $n_{F}$, but not on $n$. Therefore, with a sufficiently strong increase in $n$, raising $n_{F}$ to $\left(n_{F}^{*}+1\right)$ would be welfare increasing.

\section{Concluding remarks}

The present paper introduces a quantity leadership model with a cartel, a group of fringe firms and an antitrust authority that has three policy instruments at its disposal: its own effort, a fine for detected cartels, and a leniency program for cartel members that cooperate with the authority. Taking the cost of these instruments into consideration, we derive an optimal antitrust policy. We show that the antitrust authority should reduce the size of the cartel until the resulting increase in social cost (the negative cost effect) overcompensates the resulting gains in the sum of consumer and producer rent (the positive output effect).

Our analysis reveals that both, the optimal force and the optimal mix of the antitrust authority's policy depend on the characteristics of the specific market. The market characteristics include aspects such as the efficiency of the antitrust authority's operations, the public respect for the rule of law, the ethical standards of the firms' managers, the market volume, and the number of firms operating on the market. With heterogeneous markets, a one-size-fits-all antitrust policy is inappropriate. For example, suppose that there is a public attitude that collusion in the banking sector deserves particularly harsh punishment. In other words, the additional social cost from increasing the fine is low, while the social cost savings from lowering the discount are large. The antitrust authority should respond to this situation by a policy that features a larger fine and a lower discount than in other markets with, otherwise, similar characteristics.

Furthermore, our findings demonstrate that the antitrust authority should recalibrate its policy when changes in the market environment occur. For example, a small increase in the market volume should lead to small reductions of all three policy instruments. These minor adjustments would leave the size of the cartel unchanged. However, if a sufficiently strong expansion of the market volume occurs, the policy instruments should be adjusted in the opposite direction, that is, the antitrust authority should pursue a more forceful policy that induces one or more of the cartel members to become fringe firms. 
Supergames of collusive behavior assume that the cartel is completely unable to enforce the cartel agreement, while our quantity leadership model assumes perfect enforceability. Both assumptions are not well aligned with reality. The empirical evidence shows that cartels usually manage to design cartel agreements that allow for limited forms of monitoring and dispute settlement. Therefore, a promising area of future research are oligopoly models that analyze the effects of antitrust policy directed at cartels that have limited means of inducing cooperative member behavior.

Funding Open Access funding enabled and organized by Projekt DEAL.

Open Access This article is licensed under a Creative Commons Attribution 4.0 International License, which permits use, sharing, adaptation, distribution and reproduction in any medium or format, as long as you give appropriate credit to the original author(s) and the source, provide a link to the Creative Commons licence, and indicate if changes were made. The images or other third party material in this article are included in the article's Creative Commons licence, unless indicated otherwise in a credit line to the material. If material is not included in the article's Creative Commons licence and your intended use is not permitted by statutory regulation or exceeds the permitted use, you will need to obtain permission directly from the copyright holder. To view a copy of this licence, visit http://creativecommons.org/licenses/by/4.0/.

\section{References}

Albæk, S. (2013). Consumer welfare in EU competition policy. In C. Heide-Jørgensen (Ed.), Aims and values in competition law (pp. 67-88). Copenhagen: DJØF Publishing.

Allain, M. L., Boyer, M., Kotchoni, R., \& Ponssard, J. P. (2015). Are cartel fines optimal? Theory and evidence from the European Union. International Review of Law and Economics, 42, 38-47.

Aubert, C., Rey, P., \& Kovacic, W. E. (2006). The impact of leniency and whistle-blowing programs on cartels. International Journal of Industrial Organization, 24(6), 1241-1266.

Becker, G. S. (1968). Crime and punishment: An economic approach. Journal of Political Economy, 76, $169-217$.

Bos, I., \& Harrington, J. E. (2015). Competition policy and cartel size. International Economic Review, 56(1), 133-153.

Brenner, S. (2009). An empirical study of the European corporate leniency program. International Journal of Industrial Organization, 27(6), 639-645.

Brito, D., \& Catalão-Lopes, M. (2011). Small fish become big fish: Mergers in Stackelberg markets revisited. The B.E. Journal of Economic Analysis \& Policy, 11(1), Article 24.

d'Aspremont, C., Jacquemin, A., Gabszewicz, J. J., \& Weymark, J. A. (1983). On the stability of collusive price leadership. The Canadian Journal of Economics, 16(1), 17-25.

Daughety, A. F. (1990). Beneficial concentration. American Economic Review, 80(5), 1231-1237.

Donsimoni, M. P. (1985). Stable heterogeneous cartels. International Journal of Industrial Organization, 3(4), 451-467.

Donsimoni, M. P., Economides, N., \& Polenachakis, H. (1986). Stable cartels. International Economic Review, 27(2), 317-327.

EC. (2003). Official Journal of the European Union, L 255/1, 8.10.2003, Case C.37.519 -Methionine, Decision of July 2, 2002.

EC. (2010). Commission Decision of 30.06.2010, C(2010) 4387 final, COMP/38.344 - Prestressing Steel.

EC. (2011). Press Release IP/11/403, 04.04.2011, https://ec.europa.eu/commission/presscorner/detail/en/ IP_11_403.

Harrington, J. E. (2013). Corporate leniency programs when firms have private information: The push of prosecution and the pull of pre-emption. The Journal of Industrial Economics, 61(1), 1-27.

Huck, S., Konrad, K. A., Müller, W., \& Normann, H.-T. (2007). The merger paradox and why aspiration levels let it fail in the laboratory. The Economic Journal, 117, 1073-1095.

Konishi, H., \& Lin, P. (1999). Stable cartels with a Cournot fringe in a symmetric oligopoly. KEIO Economic Studies, 36(2), 1-10.

Lofaro, A. (1999). When imperfect collusion is profitable. Journal of Economics, 70(3), 235-259. 
Martin, S. (1990). Fringe size and cartel stability. EUI working papers in economics, No. 90/16.

Motta, M. (2004). Competition policy: Theory and practice. New York: Cambridge University Press.

Prokop, J. (1999). Process of dominant cartel formation. International Journal of Industrial Organization, 17(2), 241-257.

Shaffer, S. (1995). Stable cartels with a Cournot fringe. Southern Economic Journal, 61(3), 744-754.

Thoron, S. (1998). Formation of a coalition-proof stable cartel. Canadian Journal of Economics, 31(1), 63-76.

von Auer, L., \& Pham, T. A. (2020). Optimal destabilization of cartels (December 11, 2020). https://ssrn. com/abstract $=3746877$.

Wilson, C. S. (2019). Welfare standards underlying antitrust enforcement: What you measure is what you get. In Luncheon keynote address delivered at the George Mason law review 22nd annual antitrust symposium, Arlington, VA.

Zu, L., Zhang, J., \& Wang, S. (2012). The size of stable cartels: An analytical approach. International Journal of Industrial Organization, 30(2), 217-222.

Publisher's Note Springer Nature remains neutral with regard to jurisdictional claims in published maps and institutional affiliations. 